\title{
Animalidad en las películas de Pier Paolo Pasolini
}

\section{Animality in Pier Paolo Pasolini's Films}

\author{
Valeria de los Ríos \\ Instituto de Estética, Facultad de Filosofía, Pontificia Universidad Católica \\ de Chile. Santiago, Chile. \\ edelo@uc.cl
}

\section{Resumen}

El presente artículo estudia el problema de la animalidad en tres películas del director italiano: Uccellacci Uccellini (Pajaritos y Pajarracos, 1966), Porcile (Pocilga, 1969) y Salò (1975). La figura del animal está presente en estas películas para señalar el límite de lo humano o aquello que sencillamente está fuera de lo humano. La figura del animal tiene en Pasolini un rendimiento a la vez estético (a partir de su teoría del "cine de poesía") y político que pone en tensión las divisiones tradicionales o modernas entre lo humano y lo animal.

Palabras clave: Pasolini, animalidad, biopolítica, impolítico.

\section{Abstract}

This paper studies the problem of animality in three films by the Italian director Pier Paolo Pasolini: Uccellacci Uccellini (Hawks and Sparrows, 1966) Porcile (Pigsty, 1969) and Salo (1975). The figure of the animal is present in these films to mark the limit of the human or to show what is simply out of the human realm. The figure of the animal has in Pasolini's films an aesthetic (his "cinema of poetry") as well as a political productivity, which strains the traditional or modern divisions between the human and the animal realms.

Keywords: Pasolini, Animality, Biopolitics, Unpolitical. 
La primera imagen que suscita la pregunta por la presencia animal o la animalidad en el cine de Pier Paolo Pasolini es, por supuesto, la de la última película que el director italiano filmó: Salo o le 120 giornato di Sodoma (1975), en la que acudimos a la escenificación del fascismo. Se trata de la representación de un régimen totalitario en el que gobierna la lógica del campo de concentración, tal como Giorgio Agamben la describe en Homo Sacer (1995). Agamben -quien a los 22 años actuó como apóstol en la película de Pasolini El evangelio según San Mateo (1964) - sostiene que la soberanía ${ }^{1}$ supone una relación especial con la vida humana en términos biológicos, que ha sido dividida en dos acepciones de raíz griega: bios y zoé. Zoé se refiere a la "vida nuda" y bios a la vida calificada o reconocida políticamente como vida ciudadana o humana en un sentido moral. La "vida nuda" o zoé, en cambio, está estrechamente vinculada a la vida animal, pues es la vida que compartimos con los animales por el simple hecho de estar vivos. El homo sacer es la figura en la que se concentra la noción de la "vida nuda", puesto que puede ser asesinado, pero no sacrificado, es decir, puede ser eliminado en impunidad.

En los regímenes modernos, los estados de excepción se arrogan el poder de decidir quiénes pueden ser declarados homo sacer, en otras palabras, quiénes pueden ser definidos como "monstruos", "animales" o menos que personas, suspendiéndoles con ello garantías legales, protección y derechos. Para Agamben, los campos de concentración transforman los estados de excepción en algo permanente. El homo sacer o renegado pierde la posibilidad de salir al exilio y se queda suspendido entre un interior y un exterior, por lo que se encuentra en permanente peligro, a merced de un poder por completo arbitrario. En el campo de concentración, entonces, los sujetos fuera de la ley son definidos como poseedores de una vida que no merece ser vivida. Ese espacio cerrado del campo es el que escenifica Salò, un espacio donde el poder se infringe sobre los cuerpos, puesto que es la vida como zoé la que allí se pone en juego; una vida no calificada, aquella que puede ser eliminada sin mediar castigo.

En Salò, el grupo de jóvenes -hombres y mujeres- homo sacer es conducido a un palazzo italiano por un grupo formado por un duque, un obispo, un juez y un banquero. Al llegar al lugar - un edificio adornado al estilo modernista, decorado con muebles art decó y pinturas vanguardistas-, uno de los líderes lee el reglamento que anuncia la suspensión de toda legalidad -se anuncia que los jóvenes ya están muertos para el mundo- y se prefigura la animalización de estos sujetos, que son obligados a desplazarse desnudos y en cuatro patas, a comer lo que les dan (incluso excrementos) como si fuesen perros. No hay función física o corporal -la condición biológica de la vida- que no esté implicada en esta dominación perversa. Luego de pasar por "El círculo de las manías"

1 Es justamente esta centralidad de la noción de soberanía la que ha atraído críticas a los postulados de Agamben. Para Foucault, quien primero formula la noción de biopolítica, la soberanía es un marco demasiado amplio, abstracto y rígido, que él opone a la noción de gubernamentalidad. La biopolítica, según Foucault, surgiría justamente cuando se abandona el marco de la soberanía y cuando la población -como dato, como campo de intervención- aparece como el fin último, y por excelencia, del gobierno. 
y "El círculo de la mierda", los jóvenes son enfrentados a "El círculo de la sangre", fase final en la que los cuerpos de los condenados son sometidos a suplicios extremos.

En su análisis de Salò, Eduardo Subirats define la tortura como la más íntima expresión del logos de dominación (175). Así, el terror del campo de concentración, lejos de prefigurarse como un espacio irracional, se presenta como una metáfora de la civilización o el logos moderno. Haciendo una lectura de Sade - uno de los textos inspiradores de Salò-, Subirats afirma que la misma racionalidad que sostenía los ideales iluministas republicanos de libertad e igualdad servía para perpetuar el nihilismo del aparato estatal, caracterizado por el poder genocida, el dispositivo militar, la opresión, la destrucción, la violencia y la humillación (177). Tal como uno de los libertinos declara en la película, es sólo a través de la tortura que se puede realizar la libertad trascendental de la razón técnico-científica, ya sea como fantasía omnipotente o como deseo de una anarquía total (178). Así, resulta aterrador que los suplicios ejercidos sobre esos cuerpos como pura materia viviente se presenten como una expresión de libertad, soberanía y poder imperial.

En Salò, el animal como metáfora señala al sujeto como homo sacer, esa vida puramente biológica, que carece de derechos y de todo tipo de protección, una vida no calificada, que en definitiva no merece ser vivida. En el palacio como campo de concentración la animalización no es la excepción, sino la regla, ya que podemos llamar animales tanto a los opresores como a los oprimidos. Este es el resultado final de lo que Agamben llamó la “máquina antropocéntrica”. En Lo abierto, Agamben propone que esta maquinaria que define al hombre siempre ha sido el resultado de una división y una articulación entre lo animal y lo humano (cit. en Anderson y Past 5), es decir, la noción de "hombre" ha sido históricamente el resultado de la contraposición con el animal como su máxima alteridad.

En Porcile (1969) Pasolini presenta dos versiones de la alteridad: la de un caníbal que funda una secta en los faldeos del monte Etna y la de un joven de la burguesía acomodada que practica la bestialidad, es decir, el sexo con animales. La elección de estas temáticas extremas responde al propósito explícito de hacer un cine "inconsumible", esto es, un cine imposible de tragar, un cine indigerible, que se resiste con toda su potencia a convertirse en mercancía. Un cine de esta naturaleza no puede ser reducido a una lectura alegórica y es imposible que su sentido pueda ser sintetizado en conceptos claramente racionalizables. Justamente, su fuerza y contemporaneidad reside en esta resistencia a entrar en la lógica de la interpretación ${ }^{2}$.

2 Resulta interesante destacar que en la poética de Pasolini la comunicación a través del cine (que él llama "visiva"), a diferencia de la comunicación instrumental, resulta tosca, "casi animal": "Tanto la mímica y la realidad bruta como los sueños y los mecanismos de la memoria, son hechos casi pre-humanos, o que se hallan en las fronteras de lo humano: en cualquier caso, pre-morfológicos (los sueños aparecen al nivel del inconsciente, y también los mecanismos mnemónicos; la mímica es un signo de extrema elementalidad civil, etc.). El instrumento lingüístico sobre el cual se implanta el cine es por tanto de tipo irracional: y esto explica la profunda cualidad onírica del cine, y también su imprescindible concreción, digamos, objetal” (13). Esta cualidad del lenguaje cinematográfico hace que la lengua del cine sea una "lengua de poesía" (Pasolini, "Cine de poesía" 18). 
Porcile -traducida al español como Pocilga, lugar que define la porqueriza donde habitan los cerdos- está dividida en dos grandes relatos. Ambos recurren a tabúes antropológicos para señalar un espacio de alteridad. La historia de antropofagia se sitúa en un pasado preindustrial, en que la existencia del homo sacer se vincula al aislamiento en un espacio inhóspito y al consumo de criaturas del monte -como mariposas y serpientes- para sobrevivir. Este renegado se encuentra con otro hombre, lo asesina y lo come. El paisaje volcánico deshabitado, pero sobre todo la ausencia casi absoluta de lenguaje es lo que marca cinematográficamente este "estar fuera de lo humano". La sección filmada en el monte Etna semeja una película muda, en la que su protagonista enuncia un solo parlamento final, como una especie de autoafirmación: "He matado a mi padre, he comido carne humana y tiemblo de alegría". Al final de la historia, la secta de transgresores es denunciada y sus integrantes condenados al suplicio de quedar estacados y abandonados a la intemperie, a merced de una jauría de perros que se aproxima a devorarlos. Ninetto Davoli, uno de los actores paradigmáticos del cine de Pasolini, es un representante del pueblo que observa como testigo el exterminio de los caníbales, y es el único nexo que une a las dos historias relatadas en la película.

En la segunda historia, un coro que representa al pueblo anuncia que Julian ha sido devorado por los cerdos. Esta parte de la película, situada en una villa alemana en 1967, tiene como protagonista a Julian Klotz, un joven burgués protagonizado por el ícono de la nueva ola francesa, Jean Pierre Léaud, quien se resiste tanto a conformar el destino moldeado para su clase, como a participar en los movimientos estudiantiles revolucionarios de esos años. Su padre es un empresario acomodado que compite con el señor Herditze, quien resulta ser un ex criminal nazi que ha recurrido a la cirugía plástica para ocultar su pasado vinculado a la experimentación y exterminio de judíos. Ante la revelación del pasado nazi de Herditze, Klotz se enfrenta al descubrimiento de la zoofilia practicada por su único heredero. Estas revelaciones culminan en una alianza comercial y en un pacto de silencio que se verbaliza con la expresión del intercambio enunciado como una "historia de cerdos por una historia de judíos”. Así, en Porcile la máquina antropocéntrica se manifiesta en la utilización diegética de la metáfora animal.

Ida -interpretada por otro ícono de esos años, Anne Wiazemsky- le dice a Julian que ambos son burgueses y que por ello deben ser analizados de acuerdo a su privilegio (en la escena observamos el lugar ostentoso donde habitan y a Ida vistiendo un abrigo de piel, marca de su clase). Luego, los padres de Julian se refieren a sí mismos como "cerdos” y se preguntan sobre el futuro de Julian como tal: “¿Cuándo empezará Julian a engordar como cerdo?, ¿o a llamarme 'cerdo'?”, se pregunta el Sr. Klotz. Así, los destinos posibles que se trazan para Julian son o convertirse en cerdo o acusar a los cerdos: o bien transformarse en un burgués como su padre o bien denunciar a la burguesía. Sin embargo, Julian no escoge ninguna de estas opciones y, en lugar de ello, practica la bestialidad como un tipo de amor. La porqueriza se convierte en un espacio de resistencia o de disenso, que se manifiesta en la forma en que la porque- 
riza es registrada, en tono documental, como una realidad díscola que se cuela en la ficción, con sonido ambiente y con los silbidos de Julian sincronizados.

Este espacio de disenso o de indefinición que simboliza la porqueriza se reafirma como gesto impolítico ${ }^{3}$ en el estado catatónico en que entra Julian, una condición que oscila entre la vida y la muerte, como un último acto de rebelión, tal como lo afirma Simona Bondavalli (416) en su análisis del film. El tono de la película es abiertamente grotesco, incluso de modo diegético, ya que el Sr. Klotz anuncia que los tiempos de Brecht y de Groz aún no han terminado. Tal como implica Bondavalli, la porqueriza y los cerdos, como máxima alteridad, son la negación o un afuera del mundo burgués institucionalizado.

Hay algo en la temporalidad de la crisis que señalan estas películas que parece referir al artículo de las luciérnagas, publicado por primera vez en 1975. Allí Pasolini constata que tras la caída histórica del fascismo en Italia emergió otro fascismo vinculado a la modernización, a la obliteración de las sociedades más antiguas, arcaicas y pre-industriales (Casarino 29), el cual Pasolini simboliza con la desaparición de una especie animal o, más precisamente, de un insecto: las luciérnagas. Tal como señala Bondavalli, Pasolini tuvo una relación controversial con los movimientos estudiantiles de la segunda mitad de los años sesenta en Italia, ya que criticaba la obsolescencia del lenguaje marxista utilizado por los estudiantes italianos, un lenguaje que descansaba sobre bases racionalistas, que fallaba en apuntar a la novedad del poder neocapitalista surgido por esos años. Según el director y escritor italiano, la transformación materialista de la sociedad italiana no podía ser criticada con los mismos medios racionales que el poder consumista utilizaba para controlarla: un lenguaje exacto, transparente y técnico que diseminaba un sentido de libertad, seguridad y felicidad que sólo contribuía a enmascarar otras formas de dominación (Bondavalli 408-9).

En Uccellaci Uccellini (1966, traducida como Pajaritos y pajarracos), una película en blanco y negro, aparece otra figuración animal, que sirve esta vez como contrapunto a la versión biopolítica. Totó - un famoso comediante italiano- y Nino (Ninetto Davoli), padre e hijo, recorren las calles sin un destino claro para el espectador. La dislocación del espacio, caracterizado por una incipiente modernización, queda inscrita a partir de los numerosos letreros carreteros que anuncian distancias inusitadas, como Cuba y Estambul. Maurizio Viano señala que esta película, junto a otras como Los subersivos (1967) de los hermanos Vittorio y Paolo Taviani y Antes de la revolución (1964) de Bernardo Bertollucci, pertenece a un grupo de películas "de crisis", caracterizadas por un doble motivo de desilusión y la necesidad e imposibilidad de refundar un futuro (Viano 147). Según Viano, esta crisis está en parte motivada por la muerte, en 1964,

3 Para Roberto Espósito -quien define el concepto de lo impolítico en su Categorías de lo impolítico-, no hay otra realidad que la del poder; por ello, el conflicto es la única realidad de la política. Lo impolítico implicaría la búsqueda de una "tercera vía" que escapa a la representación teológico-política, sin ceder a la despolitización moderna. En otras palabras, lo impolítico para Espósito no sería ni lo apolítico ni lo antipolítico, sino un modo deconstructivo y a la vez crítico de mirar lo político. 
del líder del Partido Comunista italiano Palmiro Togliatti. En el prefacio al guion de la película, Pasolini anota que por ese entonces las palabras "individuo" y "pueblo" estaban perdiendo su sentido. El individuo estaba siendo transformado en el ejecutor programado del deseo multinacional y el pueblo no podía ser recipiente de los ideales populares, puesto que se estaba convirtiendo en una masa indiferenciada (Viano 148).

Al comienzo de la película, aparece como epígrafe un fragmento de una entrevista a Mao Tse Tung en la que se le pregunta: “Hacia dónde se dirige la humanidad?”, y la respuesta de Mao es: “Bah!”. Para Viano, la película se estructura así como cómica y política al mismo tiempo (149), con un eje puesto en la pregunta sobre el futuro incierto, pero con un claro anclaje en el pasado. Uccellaci Uccellini adquiere la apariencia de una fábula, puesto que en ella se introduce a un pájaro parlante, un cuervo que acompaña en su peregrinación a Totó y Nino. El cuervo -como uno de esos intelectuales de izquierda que existían antes de la muerte de Togliatti, según indican los intertítulos- relata una fábula de animales, situada en el siglo XII, que involucra a San Francisco de Asís. El santo envía al padre Ciccillo y al padre Ninetto -interpretados por los mismos actores protagonistas- a predicar el amor de Dios a los pájaros, específicamente a los halcones y los gorriones, que viven en un estado de enfrentamiento permanente. Luego de que los monjes logran aprender el lenguaje de cada una de las especies -el canto de los halcones y los saltos de los gorrionescomunican la noticia divina; sin embargo, a pesar de haber transmitido el mensaje, halcones y gorriones se siguen enfrentando, tal como lo evidencia el plano en que un halcón ataca a un gorrión después de la supuesta "conversión".

En la narrativa del padre y el hijo que recorren sin rumbo la carretera, esta relación de poder y de dominación se ejemplifica en dos situaciones: en la primera, Totó acude a la casa de sus arrendatarios, que viven en la miseria, para exigirles el pago del arriendo. En la segunda, Totó y su hijo van a la casa de un ingeniero, un burgués acomodado, en medio del desarrollo de una fiesta, para explicarle el no pago de su deuda. Al llegar, son atacados por dos enormes perros y el propio ingeniero aparece en escena escoltado por dos pastores alemanes adiestrados. Mientras Totó, arrojado en el suelo con un perro encima, se deshace en explicaciones, el ingeniero le dice que él sólo es un hombre de negocios, por lo que deben pagarle o simplemente irán a la cárcel. En la película hay referencia a la defensa y violación de la propiedad privada en clave cómica, lo que hace pensar en una crítica al capitalismo industrial, pero también se introduce metraje documental, con escenas del funeral de Togliatti, lo que llama a una lectura más política.

La inclusión de esa secuencia, junto con la escena de Porcile, con los cerdos en la porqueriza, remite a un ingreso de lo real (en clave indicial) en la ficción, ingreso que desestabiliza los límites entre los géneros y señala un fuera de la diégesis. Luego de la secuencia del funeral del líder comunista, el cuervo parlante está de un humor melancólico -recordemos que es un intelectual de izquierda- y se lamenta por el ocaso de las ideologías y de sus propias creencias. Totó llama al cuervo "doctor", apelando 
a sus amplios conocimientos intelectuales, y el cuervo le dice que si uno se come al profesor se transforma en él. Esta lección metafórica es la que Totó y Nino ejecutan en clave literal al final de la película, ya que deciden engullir al cuervo. Vemos la escena de captura, que es detenida en un fotograma, pero no la de la ingesta. Solo presenciamos al final los restos de la fogata y fragmentos del cuerpo mutilado y algunas plumas del cuervo, mientras el montaje muestra a Totó y a Nino caminando hacia la puesta de sol, como en el final de una película de Chaplin. En el horizonte despega un avión, signo de modernidad. La canción introducida al final de la película es la misma de los créditos, y señala que todo termina y comienza de la misma manera, poniendo en suspenso un cierre definitivo de esa narrativa de dominadores y dominados.

En estas tres ficciones, Pasolini recurre a los animales como elementos expresivos: el animal es la máxima alteridad en Porcile, y en Salò se convierte en la regla general, pues dominadores y dominados son animalizados, como si todo el espacio social se hubiera convertido en porqueriza. El acto caníbal en Porcile se encuentra espejeado e invertido en el consumo final del cuervo en Uccellacci Uccellini, ya que en ambas escenas vemos, por efecto del montaje, los restos del acto y no su consumación, que ocurre fuera de campo. Hasta cierto punto, si en Salò y en Porcile se comprende al animal como lo opuesto a lo humano, en Uccellacci Uccellini se expone el animal antropomorfizado; de ahí que su asesinato e ingesta tengan algún componente antropofágico. En todos estos casos el animal es una metáfora que sirve como contrapunto para definir lo humano, es decir, se escenifica la máquina antropocéntrica para criticarla como construcción cultural.

Si consideramos estos ejemplos en orden cronológico -Uccellacci Uccellini, Porcile, Salò-, advertimos una progresión hacia la animalización, en un gesto claramente pesimista, que termina con la configuración biopolítica del campo de concentración. Sin embargo, en Uccellacci Uccellini todavía Pasolini mantiene una cierta confianza -que podríamos llamar "afectiva" - en el pueblo. Esto se aprecia claramente en el empleo de la fábula como relato formativo de carácter popular, con animales antropomorfizados como protagonistas, pero también en el uso de la música en los créditos al inicio y al final de la película, compuesta por Ennio Morricone (quizás una de los mejores aperturas musicales en la historia del cine), y en la escenificación del baile coreográfico al comienzo del film.

En los créditos, el carácter popular de la música apela directamente al espectador, mientras que en la escena de la coreografía las fuerzas vitales de la juventud, el baile como performance corporal y la comicidad popular poseen todavía un potencial político, reflejado en el cine como objeto estético, poético y transformador. Como dato curioso, la secuencia coreográfica se inicia con una conversación sobre si Nino ha cerrado bien el establo de las vacas (lo que configura a los personajes como provenientes de un mundo rural que se está perdiendo), mientras que en el bar periférico, a orillas de la carretera en construcción, la música proveniente de una máquina es cifra de modernidad. Los jóvenes y el trabajador se unen al baile sin distinción de 
origen, clase ni orientación sexual, en una performance colectiva que forma otro tipo de comunidad. Finalizado el baile, Totó le pregunta al barman si se peina con la aspiradora y, en lugar de respuesta, escuchamos el sonido de aves -pajaritos y pajarracos- fuera de campo.

\section{Referencias}

Agamben, Giorgio. Homo sacer. El poder soberano y la nuda vida. Trad. Antonio Gimeno. Valencia: Pre-Textos, 1998. Medio impreso.

---. Lo abierto. El hombre y el animal. Trad. Flavia Costa. Buenos Aires: Adriana Hidalgo, 2006. Medio impreso.

Bondavalli, Simona. "Lost in the pig house: vision and consumption in Pier Paolo Pasolini’s 'Porcile”. Italica 87.3 (2010): 408-427. Medio impreso.

Espósito, Roberto. Categorías de lo impolítico. Buenos Aires: Katz, 2006. Medio impreso. Foucault, Michel. Seguridad, Territorio, Población. Buenos Aires: Fondo de Cultura Económica, 2006. Medio impreso.

Pasolini, Pier Paolo. "Cine de poesía". Pier Paolo Pasolini contra Eric Rohmer. Cine de poesía contra cine de prosa. Barcelona: Anagrama, 1976. 9-41. Medio impreso.

Porcile. Dir. Pier Paolo Pasolini. Act. Pier Clémenti, Jean-Pierre Léaud, Alberto Lionello. I Film Dell'Orso/INDIEF /IDI Cinematografica/ CAPAC, 1969. Medio fílmico. Salò o le 120 giornate di Sodoma. Dir. Pier Paolo Pasolini. Act. Paolo Bonacelli, Giorgio Cataldi, Umberto Paolo Quintavalle. PEA/ Les Productions Artistes Associés/ United Artists, 1975. Medio fílmico.

Subirats, Eduardo. “Totalitarian Lust: From Salò to Abu Ghraib”. Trad. Christopher Britt-Arredondo. South Central Review 24.1 (2007): 174-182. Medio impreso. Uccellacci Uccellini. Dir. Pier Paolo Pasolini. Act. Totò, Ninetto Davoli, Femi Benussi. Arco Film, 1966. Medio fílmico.

Viano, Maurizio. A Certain Realism. Making use of Pasolini's Film Theory and Practice. Berkeley, Los Angeles, London: University of California Press, 1993. Medio impreso. 